DOI: 10.20472/IAC.2017.33.071

\author{
MARIA TUMBEVA \\ New Bulgarian University, Bulgaria \\ ELMIRA BANTCHEVA \\ New Bulgarian University, Bulgaria
}

\title{
THE TALENT MANAGEMENT - A REAL CHALLENGE FOR SKF BEARINGS BUSINESS IN BULGARIA
}

\begin{abstract}
:
The Talent Management topic is extremely extensive. At a time of global economic recession (2016) and a subsequent boom in the first quarter of 2017, unclear markets, great pace of change, and an extreme need for flexibility, each organization relies on its talents to overcome them. Good practices show that they best deal with the "crisis" of companies in which there are built-up, robust talent management processes and continuity planning.

This topic is a real challenge for SKF Bearings company in Bulgaria witch consists of three independent plants located in the town of Sopot, the town of Kalofer and the village of Karnare.

In view of the demographic development of the area in which the Company is located, the problem of building up its own staff and continuity for all levels of government is at the forefront. Another challenge is the stagnation in the labor market and the lack of expertise. Bulgaria is an increasingly preferred destination for exporting labor - intensive production facilities from central Europe to automotive and not only industry. For companies, this mean that they will have to where with the available staff, which posses the challenge of retaining, re-qualifying and increasing knowledge, skills, performance and motivation.

In view of the increasing turnover in trends of the company, the task of continuity of the business processes from the point of view of the human resource is at the forefront and the implementation of a Talent Management system is with high priority for the organization. Talent Management aims to ensure that SKF has the right people in the right place in order to stimulate the business and to succeed in the market - today and tomorrow. It is about creating the right conditions for employees to maximize their potential and focus on their own development and careers.
\end{abstract}

\section{Keywords:}

talent, talent management, company strategy, business analysis, development 


\section{Introduction}

The Talent Management topic is extremely extensive. At a time of global economic recession (2016) and a subsequent boom in the first quarter of 2017, unclear markets, great pace of change, and an extreme need for flexibility, each organization relies on its talents to overcome them. Good practices show that they best deal with the "crisis" of companies in which there are built-up, robust talent management processes and continuity planning.

Companies that excel in talent management have introduced a system that is internally coherent and supports the practices they use to attract, select, develop, evaluate and retain their talents. In addition, they align these practices with their business strategy, corporate culture, and long-term goals (Beechler \& Woodward, 2009). The Boston Consulting Group report "Profitability Skills" states that companies that enjoy the highest economic performance are constantly ahead of their competitors in three areas: talent management; performance management and remuneration and leadership development (2012).

This paper focuses on the identification of talents as a strategic investment of SKF Bearings Company in Bulgaria to increase their competitiveness in the future. The paper represents partial results of a project aimed at the development and implementation of Talent management program in the specific conditions of a manufacturing company. The key question is how we can optimize the identification of the potential talents of a Production Company so that the investment in their development will not be lost.

\section{What is Talent?}

The first step in the talent management program is to clarify which employees we define as talents and what we put into the notion of a "talent".

In the New Testament, we could found the parable of the three servants, whose master gives them the coin called "talent". One has hidden his talent in the earth, the second has exchanged it, and the third has multiplied it. Hence, the three expressions: hidden (buried) talent, replaced, and multiplied (developed) talent.

In the Bible the word "talent" has spread in a transcendent sense, as a gift from God, the ability to create something new.

Modern scholars isolate certain talents /gifts/ intellect possessed by people to varying degrees. In the early 1980's Howard Gardner wrote the book "Frames of mind." In this book, he identified nine kinds of talent, intellect: Verbal-linguistic, Logic-mathematical, Musical, Body-kinetic, Visual - Space, Interpersonal, Intra-personal, Naturalistic, and Existential.

Gardner defines the individual type of intelligence as "human ability that functions as a separate system in the brain, according to its own rules." Whether a person with a certain type of intelligence will develop and use it or not depends only on himself. 
According to the theory of multiple intelligences, there is noone with only one intelligence, but with a multitude of self-intelligence that interact. To be a human being, one must be able to harness the full potential of each type of intelligence. The future belongs to those who are able to use them.

Since the Middle Ages, the word talent has evolved into the word as we know it today, describing natural abilities. Today in our modern European languages, "talent" refers to the innate gift, which is considered a gift (Tansley, 2011).

Tansley (2011) recognizes five different talent perspectives for individuals: talent as a definite behavior, combination of high achievement against high potential, talent as high potential, talent as high performance and talent as individual strengths. Strengths can be almost everything a person is good at. Because we have so many different views about what a talented person is, we have no common language to describe talent.

Stuart-Kotze \& Dunn (2008) present their idea, which focuses on what is visible and measurable - namely behavior, and defines talent as ability and opportunity to do something good. The ability refers to the current performance and potential to achieve the potential results. Burk and Ossola (2011) say that common misconceptions about talent are that talent is innate, can be bought, and that talent can be identified and developed at an early stage.

Psychologist Carol Dave has developed the concept of thinking, in which there are two types of people: those with a fixed mindset and those thinking of growth. People with a fixed mindset think that their talent is static and do not try to develop it. Meanwhile, people with growth thinking are trying to develop their talent through training and hard work (Dweck, 2013). According to Wikstrom (2012), purposeful learning is what separates the best from others. Tansley (2011) notes that Gagné presents his favorite talent definition: "talent indicates the excellent knowledge of systematically developed abilities and knowledge, at least in the field of human effort." The way in which the word talent is used suggests that it is static, and, in fact, talent can develop.

Whether in the word "Talent" we put the meaning of Howard Gardner, Tansley or Biblical sense, each organization seeks the right people to achieve their business goals.

Talents characterized with skills, experience and development potential that the company needs to meet their business goals.

Talents are not afraid of new challenges and are willing to take reasonable risks in their quest to achieve their goals. They use trust and are respected not only by their bosses, but also by their colleagues and their subordinates. They are confident in their abilities and are not afraid to admit if they do not know something or make a mistake. Permanently achieve measurable and visible results.

Managers usually have their own, unconscious definition of talent. When asked, they can more easily tell who the talented people in their team are than explain what they mean. The easiest way to define talent is by linking it individual achievements. It is easier to see who gives extraordinary results than to explain how this is done. When 
managers impose a "talented" label on someone, they put expectations in this person. Expectations not only to achieve business goals but also a certain behavioral pattern for that.

\section{Managing talents}

In 1997, McKinsey \& Company published its research on the subject, and for the first time used the term "War on Talents," which then became extremely popular.

McKinsey \& Company described it as crucial for organizations to have the right talents to compete in business based on knowledge, and it has become more difficult to attract and retain those talents (McKinsey \& Company, 2001).

In the academic world, talent management (TM) is a controversial concept. Literature review of talent management often raises the fact that there is no consistent explanation of what talent management is. Lewis \& Heckman (2006) even claim that there is a disturbing lack of clarity with regard to the definition, scope and overall objectives of Talent management. They find three recurring ideas about the importance of talent management: the first defines Talent Management as "a collection of typical human resource practices, the second idea is about talented groups, and "how to ensure an appropriate flow of staff at work in the whole organization" and, finally, the third view is for talent as a generic good resource that can be managed with high efficiency.

As an example of the first idea, Mäkelä, Björkman \& Ehrnrooth (2010) use the definition of Talent Management as "the organization's efforts to attract, select, develop and retain talented key employees." The second idea seems to be the most widespread one that focuses on specific groups of employees believed to have an "operational talent" (Mäkelä, Björkman, \& Ehrnrooth, 2010). The third idea dates back to McKinsey \& Company's definition of talent as "the sum of man's abilities, his inherent talents, skills, knowledge, experience, intelligence, judgment, attitude, character and aspiration" presented in their report when they first use the legendary phrase "War for Talent" (Beechler \& Woodward, 2009). Whelan, Collings \& Donnellan (2009) add a fourth stream of talent management, which focuses on identifying key positions that can impact the company's competitive edge. It has been established that talent management practices belonging to this fourth category have statistically more significant impacts on company attractiveness, goal achievement, customer satisfaction and corporate profits (Bethke-Langenegger, Mahler \& Staffelbach, 2011). In addition, the Bethke-Langenegger, Mahler \& Staffelbach (2011) study showed that companies that adopt talent management strategies that focus on succession planning are enjoying higher corporate profits and greater confidence and motivation. Talents could know their future career to a greater extent and see the leadership integrity. Talent management strategies aimed at their development increase the attractiveness of the employer because talents usually want to know their career opportunities, development opportunities and challenging tasks. 
Collins and Mellachii (2009) propose the definition of talent management as "activities and processes that involve the systematic identification of key positions". The advantage is the development of talents of high quality and highly effective staff to fill these roles and the design of structure of Human resources to make it easier to fill these positions with them and to ensure their continued commitment to the organization.

Blas (2009) suggests that talent management seems to be the intersection between strategy, succession planning and human resource management, using primarily development, and recruitment and retention strategie.

An increasingly popular idea in managing talent is that it should be linked to the company's strategy. It is important for the company's strategy to explain to employees how to distinguish their company from the competition. The unclear and generic strategy is not enough to guide the actions of the employees. In addition, it is crucial that the company's goals are clearly stated so that the employee can understand their role in achieving them. In addition, HR should understand why and how they could support the strategy (Becker, Huselid, \& Ulrich, The HR Scorecard, 2001).

Becker, Husseld and Beatty (2009) claim that the organization should put strategy first and not people, because each organization needs to distinguish itself from its competitors by choosing a strategy if it wants to thrive and survive. They then argue that companies should turn their workforce into a tool to implement the strategy, which also needs to be different from competition to be successful. They mark this new way of working with human capital, such as creating a differentiated strategy for the workforce. They note, however, that this is a big leap from defining the strategic capabilities of a company to create a differentiated strategy for the workforce because the missing link is often that the company has to express how talent can contribute to the success of strategic potential. The first step in achieving the organization's competitive advantages is to know the business, its strategic goals and capabilities, and what activities create value in the organization. Only then the organization and talent can be managed to their maximum potential by managing the talents themselves.

The general tendency in talent management is that in order to understand the organization's talented leaders more thoroughly, it is important to classify the organization's strategic jobs. The companies need to move away from traditional approaches and have to adopt a model where the relative value of jobs is determined by the specific strategic capabilities needed to implement the strategy and then urge companies to invest more in these strategic positions (or" jobs ") and put the most talented employees in these positions.

The organizations need to segment their talents in order to identify the "central talents"the jobs, roles and competencies in which human capital will have the greatest impact on the successful implementation of the strategy.

When the strategic impact is high, the talent can significantly increase the likelihood that the strategy will be implemented and the individual performance of the person taking the position will have a great impact on performance and strategy. Choosing the wrong 
person for these roles will lead to an immediate misrepresentation and may cost a lot to the company. Strategic positions are also not automatic leadership positions, as strategic positions are independent of the hierarchy. Strategic positions are determined only by the potential to generate profits and their strategic impact.

The creation of a strategic architecture of the workforce in which all parts fit is one of the main things that can be applied in practice (Becker, Huselid \& Beatty, 2009). To manage such architecture, it is also important to measure the suitability of the elements, not just how well you implement the strategy. This system approach is important to detect possible discrepancies.

\section{Some conclusions and justifications for our project}

Although there is a debate on the definition and purpose of talent management, talent management is considered a necessity for a number of reasons: the emergence of a knowledge economy, the emergence of new generations in the workforce; Organizations needing new tools for managing human resources. Talent management is a response to many of challenges can provide competitive advantage, develop and retain valuable staff, and strategically redefine human resources management.

Collings \& Mellahi (2009) offer a comprehensive definition of talent management as: "activities and processes that involve the systematic identification of key positions that contribute to the organization's sustainable competitive advantage, finding high-energy and high-performing staff to fill these roles, and the development of a differentiated human resources structure to make it easier to fill these positions with the resources needed and to ensure their continued engagement with the organization".

The new trends in talent management reveal that there can be no best practice, as each firm needs to tailor its talent management and differentiate its workforce strategy in its context and corporate strategy in order to create competitive advantages. Therefore, there are not "right answers" within the framework of talent management. If talent management is seen as a systematic and strategic approach to HRMD, then it becomes obvious that talent management cannot be applied equally to all organizations, since no organization is the same as the other.

In addition to the apparent gap in research with regard to the definition, scope and purpose of talent management, one of the reasons why talent management needs to be further developed is that organizations have changed and the hierarchy layers have been abolished in favor of more flat organizations. Therefore, promises to the talents that they will have a fast career and get promotions are more difficult than before. As a consequence, it becomes an area of interest to encourage individuals to develop into strategic positions that can be found at every level in the organization. Managing the expectations of talented employees and motivating them to occupy strategic positions instead of managerial positions is in the organization's interest. 


\section{Profile of SKF Bearings Company and analysis of the business environment in Bulgaria (where the company operates)}

SKF establishes its production in Bulgaria in 2002. Fully automated plants meet the highest standards for the production of ball bearings and components for them and deliver products for the markets in Europe, America and Africa as well as for the main automotive manufacturers in the world Scale.

SKF in Bulgaria consists of three independent plants located in Sopot, Kalofer and Karnare.

The factories produce products according to "SKF Explorer" standard and products with a specific application according to the needs of our customers.

All three plants are certified in ISO / TS 16949: 2009, ISO 14001: 2004 and OHSAS 18001: 2007, as well as our main customers in the automotive and household appliances industries.

For the past 15 years, the continuous efforts of the management have turned a depressed, non-working, disintegrating former state-owned enterprise into a modern, workable and profitable plant that fully complies with the highest standards for the automotive industry and the HR department of a worker is currently a full-fledged strategic business partner.

In view of the demographic development of the area in which the Company is located, the problem of building up its own staff and continuity for all levels of government is at the forefront. Another challenge is the stagnation in the labor market and lack of expertise. Bulgaria is an increasingly preferred destination for exporting labor - intensive production facilities from central Europe to automotive and other industries. For companies, this means that they will have to deal with the available staff, which poses the challenge of retaining, re-qualifying and increasing knowledge, skills, performance and motivation.

In view of the trends of increasing turnover in the company, the task of continuity of the business processes from the point of view of the human resource is at the forefront and the implementation of a Talent Management system in the company is a big challenge.

The development of the business environment in Bulgaria and more specifically in the automotive market has been a major development since the beginning of 2016. The investments in the construction of manufacturing enterprises in the region of Plovdiv, where the company is located, are increasing and a zone with increased production of components mainly the automotive industry.

According to the HR department for 2015, the direct workers' turnover is below $4 \%$ and the staff over $15 \%$ with a tendency to increase in 2017 . In addition to increased recruitment and training costs, this also means a loss of knowledge and skills. As the company implements "lean" approaches, this rate of staff turnover is extremely undesirable. 
After an analysis of the reasons for staff resigning it is established that the main motive is an impossibility or an obscure path for development and the attitude and relationships with the direct manager.

The second reason is a subject of a separate study, but the unclear development path for the staff can be addressed with a well-structured and communicated talent management program.

In fact from 2008 to 2015 , there was an existing talent scrutiny scheme demanded by the parent company and set as a form oriented only to management personnel - the socalled first-line managers. The system gathers information geared mainly to the desired future development of each one in order to create a pool of potential talents, which could be used in the planning of continuity at the higher levels at a Group level, in the case of Bulgaria at the higher level in the respective production division. Everyone can evolve to the next hierarchical level or to the same level, but in a different sphere. Although working and validated, this model was more focused on preparing staff for the needs of the parent company and does not meet the needs of intra-company talent management. The model also does not have management of continuity.

Having in mind the new circumstances and the structural changes in the parent company the plant in Bulgaria start to rethink some key management processes focused on the People as the most valuable asset to the company. Their management and development processes have been put on the agenda with a strong emphasis on talent management. The first step in this process is the talent identification.

\section{Description of the talent identification process}

The identification of top talent is generally critical to the success of SKF Company. To be able to build strength for key positions, it is important to know the rising stars that will play instrumental role for its achievement. Leaders must make talent a strategic priority. They are responsible for identifying and developing talent in the organisation. This involves creation of environments where anyone can contribute and learn to realise his or her potential, and increase in employee skill, abilities, and output. SKF Bearings as an employer who seek to identify talents within the organisation should create the awareness of the different ways an individual may display his or her talent and their potential to improve their performance.

\section{Challenges with talent identification}

Talenta are an intangible asset that influence the company's output and profitability. Managers must endeavor to identify such assets and nurture them to the advantage of the company. Intangible as it is, managers do not quickly identify talent due to challenges associated with it. As argued by McCall, (1998); and Spreitzer, et al. (1997), one of the challenges associated with the identification of high potentials is that these individuals are typically identified early in their career for their suitability for future jobs. 
The world is dynamic and keeps on changing. This makes it increasingly difficult for those whose talents are identified at the early years to carry their current roles to the future, which is uncertain.

MacKinnon (2013) asserts that there are a number of things that can go wrong if a talent identification programme is not well thought out or robust. These include:

1) Too narrow definition of what talent means

Some companies define talent as with a particular age or level of employee in mind. Definition of talent should be inclusive to ensure it can remain relevant at all levels in the organisation.

2) Subjectivity in identifying talent

Subjective talent identification methods are open to bias. There are two problems with subjective talent identification methods: They ignore those who have potential that senior managers are yet to recognize, and senior leaders can often clone the people they like, leading to a homogenised workforce that managers like but that may not be matched to the achievement of the organisation's strategic goals.

3) Lack of credibility among staff

Lack of credibility among staff can actually harm employee engagement and relations if schemes are associated with favouritism.

4) High long-term cost

Employers investing in an employee development programme need to be sure the money are being spent in the right places. Subjective methods of identifying talent can lead to wasted expenditure if people and schemes are not properly matched.

5) Lack of strategic focus

What is often missing in talent identification is a strategic focus. Organisations need to be clear about where they want to be in the future, and start planning their staff development programmes now to focus on that troubled waters. It is the jurisdiction of talent management to get such people onboard, who are enterprising but ensure that an organization does not suffer for the same.

We needed a common and consistent method of talent assessment that will reduce the subjectivity of individual managers, furthermore we needed a more robust classification to provide meaningful distinctions between employee talent levels. We decided to use the 9 box matrix which is a tool for assessing talent, focusing talent reviews, developing talent action plans, and supporting talent programs. Also, it is a strong visual aid to understand organizational bench strength.

In fact, the basic tools of the personal evaluation can be divided into two main groups: quantitative and qualitative. Quantitative tools include economic indicators (for example 
labour expenses, expenses of the individual personal processes) and socioeconomic indicators (absence, fluctuation, etc). Qualitative tools include motivation and content of the employee (measured by sociological researches), quality of the competences of individual staff or evaluation of their achievement. The qualitative tools are still less commonly used than the quantitative ones, though they can give the fundamental information about a company situation and its power. However, only the corrected chosen qualitative tools provide an avoidance and solution of the possible problems and so they cannot be neglected. Commonly used methods of determining the qualitative evaluation criteria (required competences) of the key management and employees are based on an analysis of the job position. The purpose of the assessment should not only be to find the current level, but mainly to predict the future, because the behaviours reflect the interests, opinions and experiences of a whole person.

Currently, in practice, there are used comparative methods for quantitative and qualitative criteria. The main criterion for identifying business talents is a performance.This shows that employees have for their work corresponding skills and motivation. This criterion is not the only one. If staff isn't successful at their positions, it may be also because their work is boring, they lack the necessary help, motivational support, or they lack the necessary means to their performance. Therefore, it is necessary to evaluate performance in addition to the individual potential. GE - McKinsey 9 quadrant grid (9 box grid) is used for a combination of performance appraisal and the potential. Performance is straightforward to assess, but potential can be more challenging and prone to bias. Breaking potential into more objective and observable criteria of aspiration, learning agility, ability, values, and engagement reduces biases and creates a consistency in the way that all employees are evaluated. There is on one side-measured power (high, average a low) and, on the other side the potential.

Figure 1: Model of the 9 boxes enclosed in the SKF. (SKF spider network 2015)

The nine box

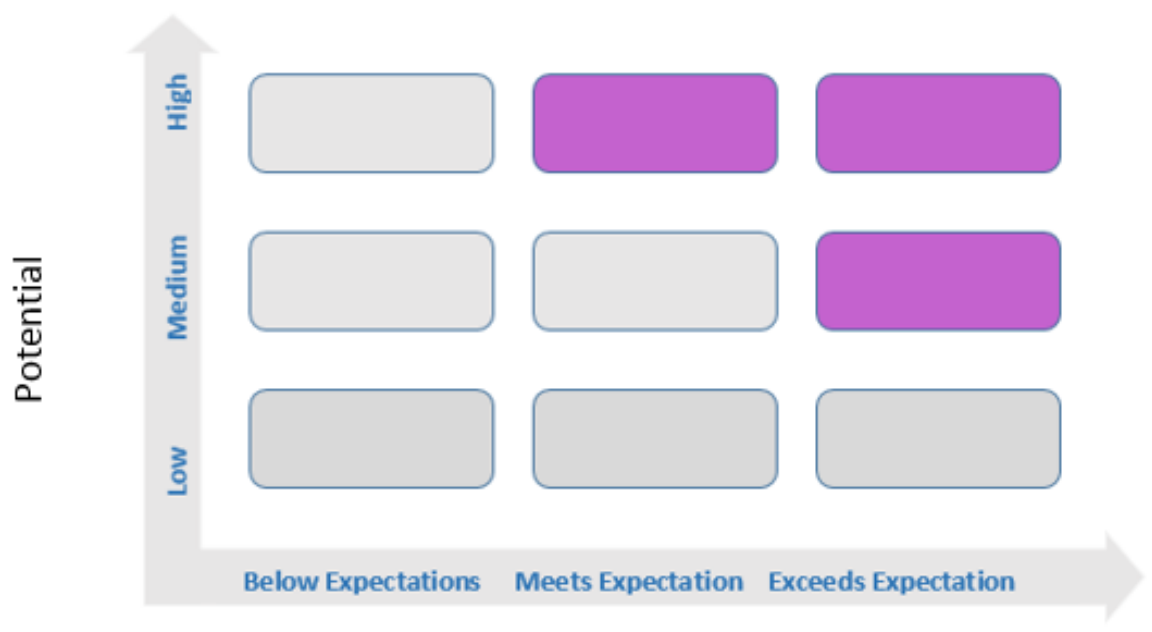

Performance 


\section{The process passes through several steps guided by the following principals:}

1. Start from the places that are most important to business strategy in order to identify opportunities for talent identification

2. Complete the analysis with several key roles in the organization.

3. Explain the purpose and the advantages of the process of the respective managers and employees.

4. Give all managers the opportunity to identify 4 people who believe they are talents.

5. Let managers write their motivation for choosing, representing talents in relation to goals, moving forces, and values.

6. Train managers to identify talent - focus on the difference between performance and potential.

7. Let the managers "sell" their candidates, motivating why they are talents.

8. Calibrate the selection, agreed on what talents are in the organization.

9. Achieve a clear definition of talent.

10. Reduce the number of selected talents.

11. Decide what to do with the talents.

12. Communicate the result with talent

The Talent pool includes 25 key people for the company - leaders and employees driving key business processes. They are divided into 3 main groups depending on the business unit to which they belong.

Table 1: Possible areas of development set out in a Model of Talent Management applied in SKF Bearings Bulgaria EAD

\begin{tabular}{|c|c|c|c|c|c|c|c|c|c|c|}
\hline \multicolumn{11}{|c|}{ DEVELOPMENT } \\
\hline \multicolumn{4}{|c|}{ OPERTIONAL } & $B U$ & \multicolumn{6}{|c|}{ SUPPORT } \\
\hline 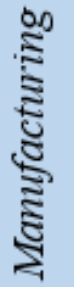 & $\frac{\stackrel{3}{\tilde{I}}}{\tilde{\omega}}$ & 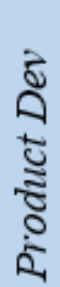 & 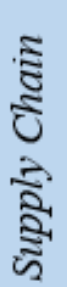 & 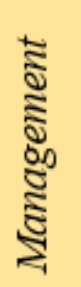 & 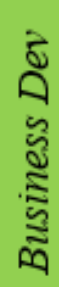 & 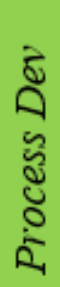 & & 䢓 & $\begin{array}{l}\text { స్ } \\
0 \\
0\end{array}$ & 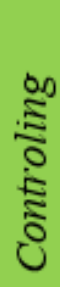 \\
\hline
\end{tabular}


Here we present the teams of two of the business units in the company and in order to preserve confidentiality, the two business units are labeled as Business Unit 1 and respectively the persons surveyed with $1.1 ; 1.2 ; 1.3 ; 1.4 ; 1.5 ; 1.6 ; 1.7 ; 1.8 ; 1.9 ; 1.10$; $1.11 ; 1.12$ and as Business Unit 2 and the persons under examination with 2.1;2.2; 2.3 ; $2.4 ; 2.5 ; 2.6 ; 2.7 ; 2.8 ; 2.9 ; 2.10 ; 2.11 ; 2.12$ and 2.13 .

One of the considered, identified as key employees and first level managers, is placed in the frame: "Performance below expected level", „Performance meeting the expected level", "Performance above the Expected Level" and based on the assessments, what potential for development each one has, the levels are: "Low", "Moderate" and "High" The matrix set in the model defines a box for everybody, respectively (See Figugure).

Figure 2: Collecting and analyzing employee data: Establishing a platform for talent identification (using different tools)

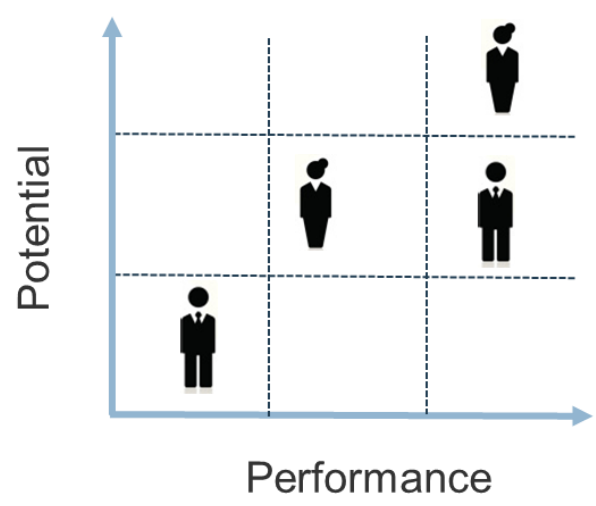

\section{Assessment Center}

An Assessment Center was planned, and implemented. We developed evaluation criteria, using the relevant company requirements for the key positions studied. The aim was to examine compliance with the following requirements:

$\checkmark$ Identify existing management competencies, style and potential as a whole, over the management competencies of the SKF Group;

$\checkmark$ Identification of individual competence and behavior, strengths and areas in need of individual /group level development;

$\checkmark$ Assesment of development needs for the planning of future individual or ongoing team development

The results obtained are summarized by individuals and teams, and used as input data for the subsequent evaluation of the talents. 


\section{Annual performance evaluation}

The other source of information used as input for talent assessment is the annual performance evaluation. It is made annually according to a company standard based on predefined competencies for each of the positions. In order to obtain the final score, the result of the fulfillment of the objectives and tasks set and the behavior demonstrated for the period is summerized, which is also compared with the predetermined behavioral model.

The assessment scores used are five and are defined as follows:

Level 1 or Unsatisfactory Achiever (UA): The required performance is either not observed or very rarely observed.

Level 2 or partial performance (PA, Partial Achiever): The required performance is sometimes observed.

Level 3 or Full Match Achievement (FA, Full Achiever): The required performance is often observed and the assessed person often achieve results as a consequence of this performance. Everyone has to meet at least that level.

Level 4 or Very Good Performance (HA, Hight Achiever): The assessed person shows constantly the required behavior and thus provides a solid support for his performance. Often he/ she demonstrates behavior that exceeds expectations.

Level 5 or Exceptional Performance (TA, Top Achiever): The assessed person has stringency and consistency in behavior, and this stimulates the colleagues and team members. Regularly demonstrates behavior that exceeds expectations. Level 5 is the anticipated model of behavior.

Besides the factual comparison of the performance with the set goals and behavior, the annual evaluation is finalized by a meeting between the direct manager and the employee. This meeting discusses what was happened at the expected level during the year as well as what was not achieved and what are the possibilities for better dealing with the same situations in any subsequent ones. The person's desires for development in the next 2 to 5 years are also discussed, their compliance with the business objectives and possible tools for this. The meeting ends with a written plan for individual development for the next 12 months, with specific actions that will lead to the elimination of the discrepancies from the expectations (if any), and actions for better performance and approaches to career aspiration.

\section{Structured interviews}

In order to collect additional information for each participant in the talent management process, we run a structured interview. Each participant was interviewed individually. The results were taken into account when discussing the completion of the career development plan and the succession planning format. 


\section{Holistic picture for everyone}

On the basis of all these activities it was possible to gather valuable information for everybody from the pool and to create a holistic picture. The information consists of 2 parts.

The first part is aimed at positioning the ratings in the model of the 9 boxes. There were comments about the development of each one received by the assessment center or as a result of conversations and aspiration of the person with the direct manager.

There is also information for the degree of readiness of the person to change. Depending on the risk, 3 categories are differentiated: No need for change, There is a need for change in the next 1 year, there is a need for change in the next 2 years

The second part focuses on the succession planning. An opportunity has been given to identify up to 4 people who could occupy the position. For each one there is an indication when he/ she would be ready: he/she is already ready; will be ready in 2 years; he/she will be ready in 5 years.

The file includes comments focused on career plans or upcoming training/ development activities. After a conversation in a working group with the direct supervisor and the head of the unit, (where possible), each one is placed within the framework: "Performance below expected level", "Performance meeting the expected level", "Performance above the Expected Level" and on the basis of the assessments, what potential for development each one has, the levels are: "Low", "Moderate", "High".

\section{Discussion of Study results}

The results (identified performance and potential) for the 25 employees from the 9 Box grid are shown in Figure 3 and Figure 4: 
Figure 3: Distribution of Key Business employees in Unit 2

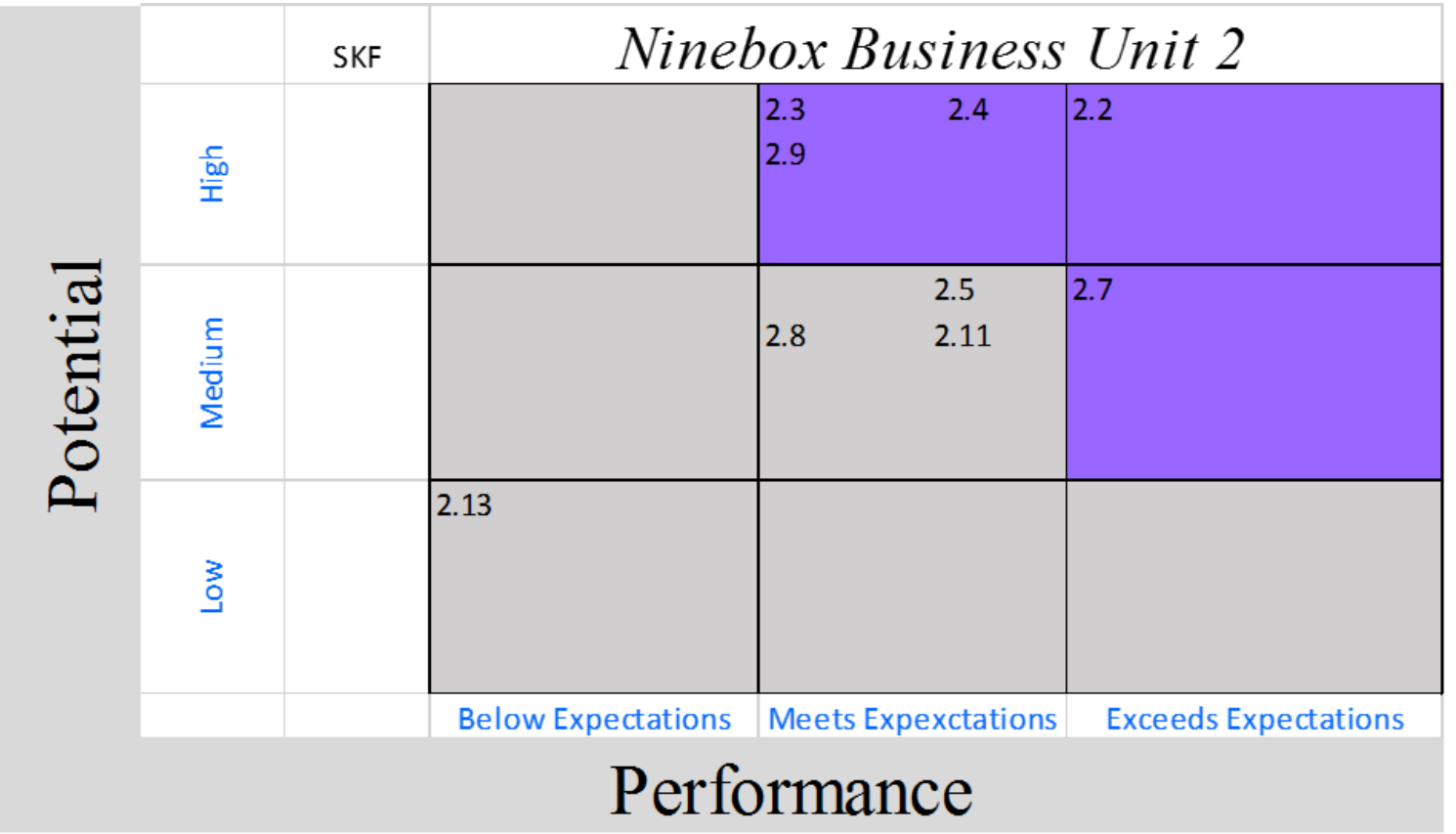

Figure 4: Distribution of Key Business employees in Unit 1

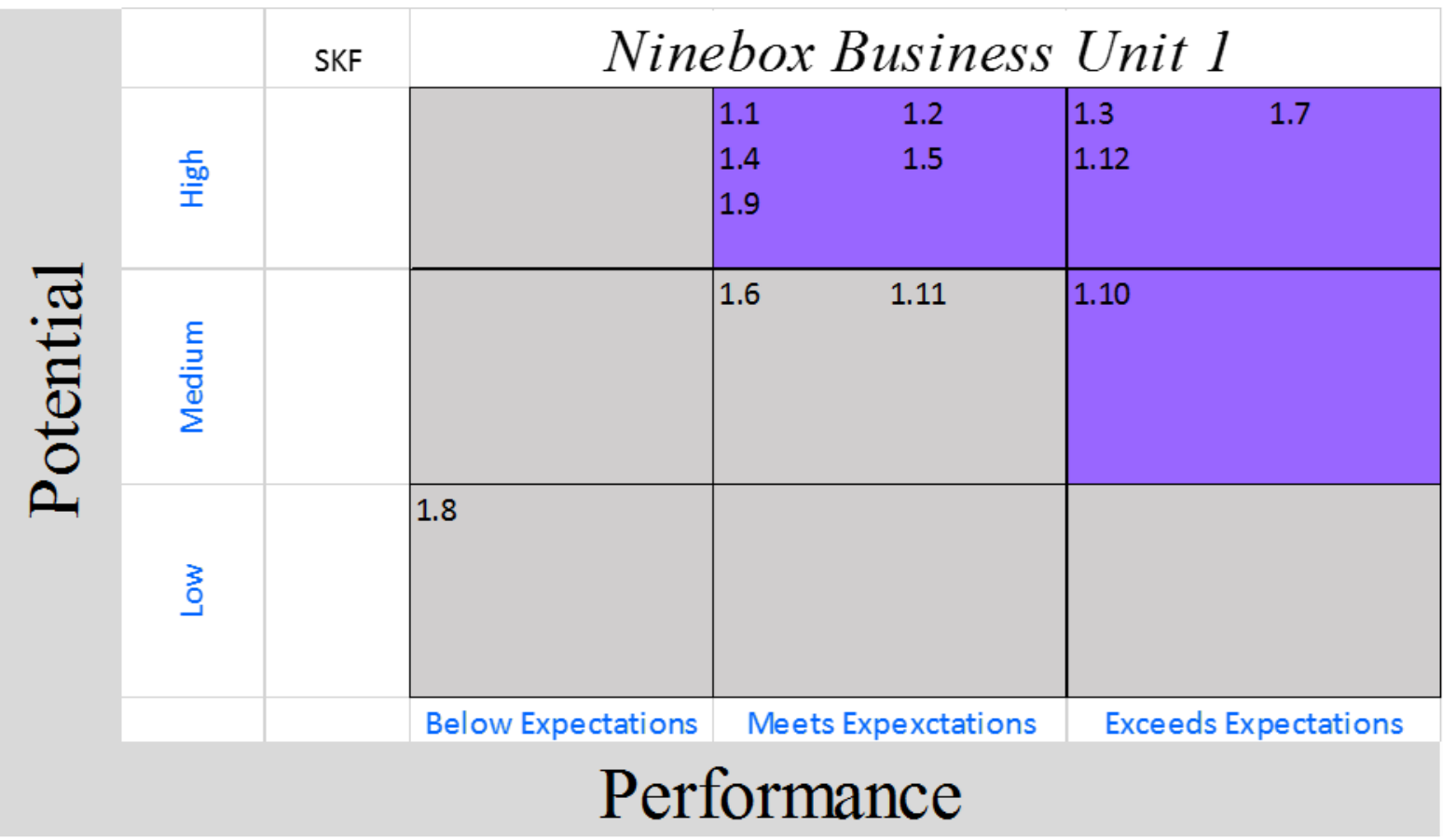

One of the Business Unit $2-2.13$ and one for Business Unit $1-1.8$ fall into the box "Performance below expectations"and "Low" Potential". In this case, a performance improvement approach should be applied together with the manager, an individual improvement plan is required, the plan should set clear short-term goals and the managers have to explicitly informed the people about what needs to be improved, also 
to provide coaching for the performance, After a certain period of time, if not performance improvement is observed a new role should be sought.

In the golden environment, or this is the box "Performance at the Expected Level "and "Moderate Potential", there are three of the key people surveyed for Business Unit 2 and two for Business Unit 1. In this position, individuals may have no desire or possibilities to continue their development. The exertion of pressure can influence them in a negative direction, and their readiness to move to the next level must be checked periodically. Also the possibility for development and training should be considered. Managers should also provide them with opportunities to "try it out". The tasks and projects that are given to them should be a little bit beyond the opportunities currently demonstrated by them in order to help them to move from" good "to" very good" performance level.Their managers need to clarify that they are valuable for the company, to hear their ideas and to encourage their achievements. But, the steps back and forth are equally possible for them. If the actions listed do not happen, it is likely to have a negative effect.

In the box described as Performance above the Expected Level and Moderate Potential, one key person comes from Business Unit 2 and Business Unit 1. They work very well. New tasks and projects that are not being implemented by them can be very challenging for them. Still, for them, the level of readiness to take on a next level of responsibility is questionable due to the moderate or still underdeveloped potential. Their development should be focused on long-term goals and tasks.

In the box "Performance in line with the expected level" and "High potential" are evaluated most of the surveyed employees, namely three from Business Unit 2 and five from Business Unit 1. This is one of the boxes in which there are the people with the so- called "desirable" for the company's performance. They could take on new projects and perform challenging tasks. Here the focus is on developing the necessary competences, which will move them from "very good" to "excellent" performance.

"Performing above the Expected Level" and "High Potential" has one representative from Business Unit 2 and three from Business Unit 1. Tasks that can be placed and challenged for them are tasks provoking their capabilities, also entirely new projects and processes aimed to deal with critical situations. They can get into a situation and resolve it. They need to be offered a high-level corporate training. The company can offer them to change the role, also a new and challenging job, or tasks with a short to medium term. They have to be stimulated by their managers to create a network of interfunctional talents from other spheres and factories. It is advisable to find a mentor standing one level above them, who could support them as well as to periodically attend meetings and projects with representatives of the same level. Periodic monitoring of early "burnout" signals should be observed. These emolyees are also at higher risk for eventual turnover. 
For each of the five distinct groups of key personnel, a different management and development approach should be applied. In each organization, the presence of most groups is quite normal and necessary, because this is related to the natural turnover, the recruitment of new staff and their development respectively. Each of the groups has its peculiarities. In order to manage them properly and to achieve high results, SKF has to apply a different approach to managing the different groups, but in order this to happen, it is necessary to have the primary proper arrangement in the 9-box model.

In conclusion, from the primary distribution in the 9-box model, the key people are divided into 5 of them, most of which fall into the three most desirable for each company boxes, namely:

\section{"Performance to the expected level" and "Moderate potential" \\ "Performance to the expected level" and "High potential" \\ "Performance above the expected level" and "High Potential"}

Follow-up of everybody, individual development plan and subsequent follow-up succession planning is required.

\section{Conclusion}

Talent Management emphasizes that SKF Bearings EAD needs to bring its strategies into line with human capital in order to be competitive. Taking into account the values of generation $Y$ (where most of the people were surveyed) - giving feedback and providing opportunities for long-term development, require managers and employees to set clear goals and evaluate often.

The philosophy of the Company is that Talent management is no longer just linked to top employees of the organisation. These positions can be anywhere and talent management truly becomes a company wide strategy. It de-links the talent management strategy from leadership development and makes talent management more contextual and dependent on the SKF business model. The success (or failure) of the business model becomes crucially dependent on designing a small number of mission-critical jobs - key positions - well.

At the same time, labeling several employees as talents brings both benefits and risks to the organization. In order to minimize the risks, it is essential that the definition of talent is related to the behavior and knowledge that the company needs - this leads to transparency and makes the definition a part of the organization's value system.

Talent management is a way for SKF Bearing to manage its human capital as a strategic asset. The new career should be aimed at achieving a strategic position that represents a set of roles in the organization that lead to its competitive advantage. Development should be based on training at the workplace and linked to the organizational needs of 
SKF Company. Middle managers play an important role in the development of employees in the strategic direction.

\section{References}

BCG \& WFPMA (2012). Creating People Advantage

Beechler \& Woodward (2009). War for Talent, Journal for international Management, p.274-285

Becker, B. E., Huselid, M. A., \& Beatty, R. W. (2009). The differentiated workforce. Transforming Talent into Strategic Impact, Harvard Business Press

Becker, B. E., Huselid, M. A., \& Ulrich, D. (2001). The HR Scorecard - Linking People, strategy, and performance. Boston: Harvard Business School press.

Bersin, J. (2010), High-Impact Talent Management: Trends, Best Practices and Industry Solutions, Bersin, Los Angeles, CA.

Bersin by Deloitte (2016). Predictions for 2016 A Bold New World of Talent, Learning, Leadership, and HR Technology Ahead, https://www2.deloitte.com/content/dam/Deloitte/at/Documents/humancapital/bersin-predictions-2016.pdf

Bethke-Langenegger, P., Mahler, P., \& Staffelbach, B. (2011). Effectiveness of talent management strategies. European Journal of International Management Vol. 5, No. 5, 524-539.

Blass, E. (2009). Talent management: cases and commentary. Palgrave Macmillan

Burkus, D., \& Osula, B. (2011). Faulty Intel in the War for Talent: Replacing the Assumptions of Talent, Journal of Business Studies Quarterly 2011, Vol. 3, No. 2, pp. 1-9

Collings, D. G., \& Mellahi, K. (2009). Strategic talent management: a review and research agenda. Human Resource Management Review 19, 304-313.

Dweck, C.S. (2008). Mindset. The new psychology of success. Ballantine Books, New York

Dweck, C.S. (2010). Mindsets and equitable education. Principal Leadership. pgs. 26-29.

Garavan, T.N., Hogan, C. and Cahir-O'Donnell, A. (2009), Developing Managers and Leaders: Perspectives, Debates and Practices in Ireland, Gill \& Macmillan, Dublin

Garavan, T. N., Carbery, R., \& Rock, A. (2012). Mapping talent development: definition, scope and architecture. European Journal of Training and Development, Vol. 31, No. 1, p.5-24

Gardner, H. (2011). Frames of Mind: The Theory of Multiple Intelligences, Published by Basic Books, A Member of the Perseus Books Groups

Kotze, R., \& Dunn, C. (2008). Who are your best people? How to find, measure and manage your top talent. Gosport: Pearson Education

Mackinnon, R., (2013). 5 mistakes business make when creating talent identification and staff development programmes. http://extra.shu.ac.uk/ sbsblog/2013/11/5-mistakes-businesses-makewhen-creating-talent-ident ificati on-and-staff-development-programmes [Accessed 3/6/14] 
Ma"kela", K., Bjo"rkman, I. and Ehrnrooth, M. (2010), "How do MNCs establish their talent pools?", Journal of World Business, Vol. 45 No. 2, pp. 134-42.

McCall, M. W. (1998). High flyers: Developing the next generation of leaders, Boston: Harvard Business School Press

McCall, M., Lombardo, M. and Morrison, M. (1988), The Lessons of Experience: How Successful Executives Develop on the Job, Lexington Books, Lexington, MA

McKinsey \& Company. (2001). The War for Talent. McKinsey \& Company.

Spreitzer, G. M. , McCall, M. W. Jr and Mahoney, J. D. (1997) 'Early Identification of International Executive Potential', Journal of Applied Psychology 82 (1): 6-29.

Tansley, C., Harris, L., Stewart, J. and Turner, P. (2006), "Talent management: understanding the dimensions", in CIPD (Ed.), Change Agenda, CIPD, London, pp. 1-16.

Tansley, C. (2011). What do we mean by the term "talent" in talent management? Industrial and Commercial Training, 43(5), 266-274.

Whelan, E., D.G. Collings, and B. Donnellan, 2010, "Managing Talent in Knowledgelntensive Settings", Journal of Knowledge Management, 14(3), 486-504.

Wikström, C., \& Martin, H. (2012). Talent Management i praktiken. Stockholm: Ekerlids Förlag. 